\title{
Radical surgery consisting of en bloc corpectomy in recurrence after palliative surgery for spinal metastasis
}

\author{
Shurei Sugita $^{1)}$, Hideki Murakami ${ }^{1)}$, Noritaka Yonezawa ${ }^{1)}$, Satoru Demura ${ }^{1)}$, Sakae Tanaka ${ }^{2)}$ and Hiroyuki Tsuchiya ${ }^{1)}$ \\ 1) Department of Orthopaedic Surgery, Kanazawa University, Japan \\ 2) Department of Orthopaedic Surgery, Faculty of Medicine, The University of Tokyo, Japan
}

\begin{abstract}
:
Introduction: We often experience recurrence of spinal metastases after palliative surgery, even with radiotherapy. We examined the clinical outcome of radical surgery containing en bloc corpectomy for patients with recurrent spinal metastasis.

Methods: Seven patients underwent en bloc corpectomy for recurrent spinal metastases. We assessed the prognosis scores (Tomita, Tokuhashi), pre- and postoperative Frankel scale scores, operation time, intraoperative blood loss, and perioperative complications.
\end{abstract}

Results: The preoperative estimated prognosis was less than six months (two patients), six months to one year (two patients), and over one year (three patients), according to Tokuhashi score. Major perioperative complications were dura mater injury and pleural injury. Neurological improvement was seen in four patients. All patients were ambulatory at discharge and lived longer than the preoperatively estimated life expectancy (range: seven months to four years).

Conclusions: Radical surgery consisting of en bloc corpectomy may be a therapeutic choice for patients with recurrent spinal metastases.

\section{Keywords:}

spinal metastasis, recurrent tumor, surgery, en bloc corpectomy

\section{Introduction}

Spinal metastasis is a clinically challenging condition, with a morbidity rate of approximately $30 \%$ among cancer patients. In addition, 5\% of cancer patients develop neurological deterioration during the clinical course ${ }^{1)}$. The clinical burden of these conditions is substantial due to the increasing life expectancy accompanying recent advances in oncological therapies.

The purposes of treatment for spinal metastasis are to prevent tumor recurrence, to decompress the spinal cord to avoid spinal paralysis, and to restore the alignment and stability of the spine ${ }^{2)}$. To achieve these purposes, surgical decompression and stabilization of the spine combined with radiotherapy is often used. This method has been proven to be an effective treatment ${ }^{3}$, but patients sometimes experience tumor recurrence, at rates of $32 \%-69 \%$. Surgically dealing with such recurrences is quite difficult because of preceding radiation, scar tissue formation, and conglutina- tion of the dura mater.

Under these conditions, if the patients' general status is good and they can tolerate operation, we treat the recurrent spinal metastases by radical surgery containing en bloc corpectomy. We adapted the technique of total en bloc spondylectomy, as we previously reported ${ }^{6}$. We herein report the clinical outcomes of radical surgery containing en bloc corpectomy for recurrent spinal metastasis.

\section{Materials and Methods}

\section{Patients}

Between January 2011 and December 2014, 81 patients underwent surgery for spinal metastasis in our hospital. We retrospectively reviewed the records of 7 patients out of 81 patients ( 5 male, 2 female; median age: 59 years old, range: 45-65 years; Table 1) who underwent en bloc corpectomy for recurrent spinal metastases. Every patient underwent 
posterior decompression with or without posterior fixation for the first surgery. We retrospectively collected the data regarding the prognosis scores (Tomita ${ }^{7)}$, Tokuhashi ${ }^{8)}$ score), pre- and postoperative Frankel scale scores, operation time, intraoperative blood loss, and perioperative complications from the medical record.

\section{Surgical procedure}

Each patient underwent preoperative embolization of segmental arteries, including one level above and one level below the tumor site. Decompression of the spinal cord was accomplished by piece-by-piece tumor and scar resection. En bloc corpectomy was performed using a routine surgical procedure $^{6}$. The anterior column was reconstructed by a vertebral spacer packed with autograft bone. During each surgery, the range of posterior fixation was two levels above and two levels below the tumor site.

\section{Statistical analysis}

Statistical analyses were performed using the $\mathrm{JMP}^{\circledR}$ version 11 software program (SAS, Cary, NC, USA). Descriptive statistics were used to analyze the clinical information,

Table 1. Demographic Data of Patients Included in This Study.

\begin{tabular}{lccc}
\hline & Age & Sex & Tumor \\
\hline Case 1 & 64 & Male & Gastrointestinal stromal tumor \\
Case 2 & 63 & Female & Thyroid cancer \\
Case 3 & 53 & Male & Lung cancer \\
Case 4 & 45 & Male & Chondrosarcoma \\
Case 5 & 59 & Female & Breast cancer \\
Case 6 & 56 & Male & Renal cell cancer \\
Case 7 & 65 & Male & Renal cell cancer \\
\hline
\end{tabular}

demographic factors, and other test data. The continuous variables were expressed as the medians and interquartile range (IQR) or means and standard deviation (SD). The differences in the motor scores after treatment were examined using Student's $t$-test. A $P$ value $<0.05$ was considered to be statistically significant.

\section{Results}

The preoperative statuses of all patients are shown in Table 2. All patients but one were ambulatory. The preoperative estimated prognosis was less than six months (two patients), between six months and one year (two patients), and over one year (three patients), according to Tokuhashi score.

The factors related to surgical treatment are shown in Table 3. Due to preoperative artery embolization, the intraoperative bleeding amount was acceptable (median: $520 \mathrm{~g}$ ) except for in one patient $(6,240 \mathrm{~g})$. The major perioperative complications were dura mater injury (in five) and partial pleural injury (in four). Dural injuries were treated by suture, polyglycolic acid sheet, and fibrin glue. Pleural injuries were treated by suturing. No cerebrospinal fluid leakage occurred after surgery, and no pneumothorax or hemothorax requiring additional treatment occurred.

Neurological improvement was seen in four patients. All of the patients were ambulatory at discharge. Local recurrence of the tumor was observed in four patients. All of the patients lived longer than preoperatively estimated (range: seven months to four years; Table 4). Four patients were still alive at the end of the study.

\section{Illustrative case}

A 63-year-old female who had a history of thyroid cancer

Table 2. Preoperative Statuses of Patients Included in This Study.

\begin{tabular}{|c|c|c|c|c|c|c|c|}
\hline & Affected level & 1 st surgery & $\begin{array}{l}\text { Radiation } \\
\text { therapy }\end{array}$ & $\begin{array}{c}\text { Frankel scale } \\
\text { scores }\end{array}$ & $\begin{array}{l}\text { Tomita } \\
\text { score }\end{array}$ & $\begin{array}{l}\text { Tokuhashi } \\
\text { score }\end{array}$ & $\begin{array}{c}\text { Estimated } \\
\text { prognosis (month) }\end{array}$ \\
\hline Case 1 & $\mathrm{~T} 5$ & Decompression & No & $\mathrm{E}$ & 2 & 12 & $12<$ \\
\hline Case 2 & T4-6 & Decompression and fixation & No & $\mathrm{C}$ & 3 & 9 & $6-12$ \\
\hline Case 3 & $\mathrm{~T} 2-4$ & Decompression and fixation & Yes & $\mathrm{E}$ & 10 & 6 & $<6$ \\
\hline Case 4 & $\mathrm{~T} 10$ & Decompression and fixation & No & $\mathrm{E}$ & 2 & 12 & $12<$ \\
\hline Case 5 & T6-7 & Decompression and fixation & Yes & $\mathrm{D}$ & 2 & 12 & $12<$ \\
\hline Case 6 & T5-6 & Decompression and fixation & Yes & $\mathrm{D}$ & 4 & 8 & $6-12$ \\
\hline Case 7 & T11-L1 & Fixation & Yes & $\mathrm{D}$ & 8 & 6 & $<6$ \\
\hline
\end{tabular}

Table 3. The Factors Related to Surgical Treatment.

\begin{tabular}{lccccc}
\hline & excised vertebra & bleeding $(\mathrm{g})$ & operation time $(\mathrm{min})$ & dura mater injury & pleural injury \\
\hline Case 1 & T5 & 520 & 445 & yes & yes \\
Case 2 & T4-6 & 6240 & 628 & yes & no \\
Case 3 & T2-4 & 330 & 522 & no & yes \\
Case 4 & T10 & 640 & 455 & no & no \\
Case 5 & T6-7 & 450 & 506 & yes & no \\
Case 6 & T5-6 & 100 & 442 & yes & yes \\
Case 7 & T11-L1 & 605 & 503 & & yes \\
\hline
\end{tabular}



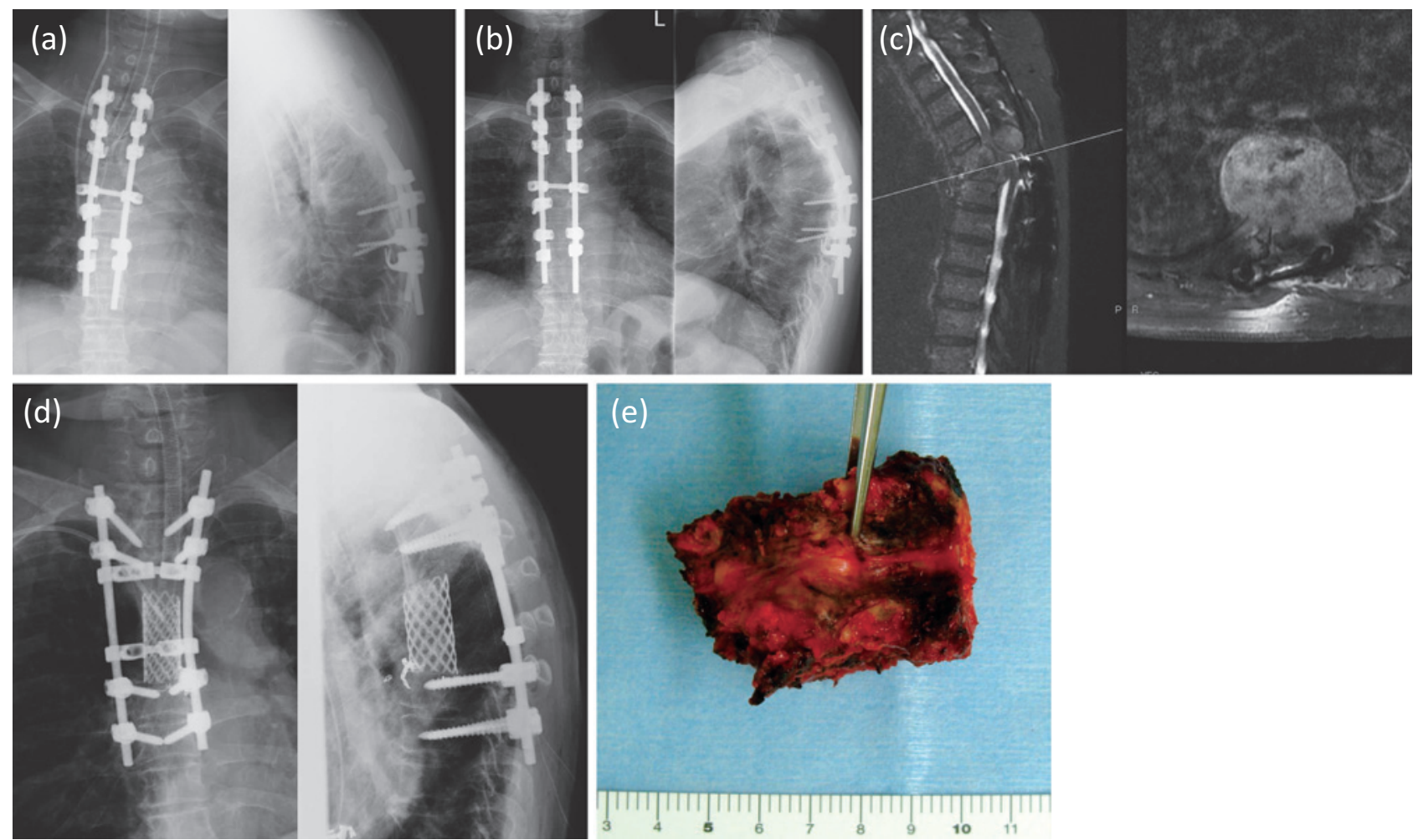

Figure 1. Plain radiographs (a) soon after the first surgery, (b) right before the second surgery. (c) MRI images of the recurrent tumor after the first surgery. (d) Plain radiographs after the second surgery. (e) Excised vertebra.

Table 4. Postoperative Outcomes of Patients.

\begin{tabular}{cccc}
\hline & $\begin{array}{c}\text { Frankel } \\
\text { scale scores }\end{array}$ & $\begin{array}{c}\text { life prognosis } \\
\text { (month) }\end{array}$ & $\begin{array}{c}\text { local tumor } \\
\text { recurrence }\end{array}$ \\
\hline Case 1 & E & 29 & Yes (1 year) \\
Case 2 & E & $48<$ & No \\
Case 3 & E & 31 & Yes (3 months) \\
Case 4 & E & $47<$ & No \\
Case 5 & D & $35<$ & No \\
Case 6 & E & $40<$ & Yes (2.5 months) \\
Case 7 & E & 7 & Yes (1.5 months) \\
\hline
\end{tabular}

and thyroidectomy 20 years prior developed paraparesis due to spinal metastasis of the thoracic spine. She underwent posterior decompression and fixation (Fig. 1a, 1b). Two years later, the tumor had relapsed; enlargement of tumor led to paraparesis again, and she became non-ambulatory (Fig. 1c). She was referred to our hospital and underwent surgery. After piecemeal resection of the posterior element of spine, en bloc corpectomy of T4 to T6 was done (Fig. 1 $\mathrm{d}, 1 \mathrm{e})$. The tumor was hypervascular, and the intraoperative blood loss was substantial $(6,240 \mathrm{~g})$. The neurological findings recovered soon (Frankel $\mathrm{C}$ to Frankel E), and she was ambulatory at discharge. She is still alive at four years after the surgery with no sign of local recurrence.

\section{Discussion}

In our study, radical surgery consisting of en bloc corpectomy was performed without life-threatening complications, and all of the patients lived longer than initially predicted before surgery. Most surgeons avoid surgical treatment of patients with metastatic spinal tumor whose estimated survival is very short. To determine the surgical indications, several scoring systems, such as the Tokuhashi score ${ }^{8)}$, Tomita score $^{7)}$, and Katagiri ${ }^{9)}$ score, are often used. However, these scoring systems differ from reality because recent advances in oncological treatment (i.e., molecular-targeting drugs) have improved the prognosis of patients with spinal metastases.

All patients included in our study had undergone palliative surgery for spinal metastases once, and the metastases had relapsed. Given these circumstances, the prognosis of these patients was anticipated to be quite grim and the life expectancy very short. Indeed, four of the seven patients were estimated before operation to survive less than one year after surgery, according to those scoring systems. However, in reality, all of them survived beyond the estimated expectancy.

The origins of metastases in these patients were thyroid cancer, lung cancer, and renal cell carcinoma, all of which could be treated by multi-modality methods. For example, metastasectomy of renal cell carcinoma has been proven to improve the prognosis ${ }^{10,11}$. In addition, molecular-targeting drugs aimed at treating lung cancer, renal cell cancer, and colorectal cancer are newly emerging ${ }^{12)}$. These present data show that patients with spinal metastases can live longer than estimated using currently available scores and be treated with aggressive surgical metastasectomy. With these circumstances, the clinical outcome of TES surgery has 
changed as we previously reported ${ }^{13-15)}$. In our hospital, now we determine the indication of TES surgery or en bloc corpectomy case by case taking consideration of all factors: age, comorbidity, affected spinal level, and size of tumor, and type of cancer.

However, aggressive metastasectomy led to an increased incidence of complications, dura mater injury $(5 / 7,71 \%)$, and partial pleural injury $(4 / 7,57 \%)$. The general incidence of postoperative complications with spinal metastases is reported to be around $20 \%{ }^{16}$. Our series showed even higher incidence, indicating the large invasiveness of this surgery. However, there were no life-threatening complications.

Several limitations associated with the present study warrant mention. First, the number of cases in this study was relatively small, so we cannot extrapolate the results of this study to larger populations in future studies. Second, all of the patients in our study were referred to our hospital for the purpose of undergoing surgery. We cannot exclude selection bias, as other patients in worse condition may have been eliminated before visiting our hospital.

\section{Conclusion}

Radical surgery consisting of en bloc corpectomy may, therefore, be a promising therapeutic strategy for patients with recurrent spinal metastases.

Conflicts of Interest: The authors declare that there are no conflicts of interest.

\section{References}

1. Gomez JA. The incidence of vertebral body metastases. Int Orthop 1995; 19: 309-11.

2. Black P. Spinal metastasis: current status and recommended guidelines for management. Neurosurgery 1979; 5: 726-46.

3. Patchell RA, Tibbs PA, Regine WF, et al. Direct decompressive surgical resection in the treatment of spinal cord compression caused by metastatic cancer: a randomised trial. Lancet 2005; 366: 643-8. eng.

4. Lau D, Leach MR, La Marca F, Park P. Independent predictors of survival and the impact of repeat surgery in patients undergoing surgical treatment of spinal metastasis. J Neurosurg Spine 2012; 17: $565-76$

5. Laufer I, Hanover A, Lis E, Yamada Y, Bilsky M. Repeat decompression surgery for recurrent spinal metastases. J Neurosurg Spine 2010; 13: 109-15.

6. Tomita K, Kawahara N, Baba H, Tsuchiya H, Nagata S, Toribatake Y. Total en bloc spondylectomy for solitary spinal metastases. Int Orthop 1994; 18: 291-8.

7. Tomita K, Kawahara N, Kobayashi T, Yoshida A, Murakami H, Akamaru T. Surgical strategy for spinal metastases. Spine. 2001; 26: 298-306.

8. Tokuhashi Y, Matsuzaki H, Toriyama S, Kawano H, Ohsaka S. Scoring system for the preoperative evaluation of metastatic spine tumor prognosis. Spine. 1990; 15: 1110-3.

9. Katagiri H, Takahashi M, Wakai K, Sugiura H, Kataoka T, Nakanishi K. Prognostic factors and a scoring system for patients with skeletal metastasis. Bone Joint J 2005; 87: 698-703.

10. Kato S, Murakami H, Demura $S$, et al. Spinal metastasectomy of renal cell carcinoma: a 16-year single center experience with a minimum 3-year follow-up. J Surg Oncol 2016; 113: 587-92.

11. Ljungberg $B$. The role of metastasectomy in renal cell carcinoma in the era of targeted therapy. Curr Urol Rep 2013; 14: 19-25.

12. Palazzo A, Iacovelli R, Cortesi E. Past, present and future of targeted therapy in solid tumors. Curr Cancer Drug Targets 2010; 10: 433-61

13. Sugita S, Murakami H, Demura $S$, et al. Repeated total en bloc spondylectomy for spinal metastases at different sites in one patient. Eur Spine J 2015; 24: 2196-200.

14. Sugita S, Murakami H, Kato S, Tanaka S, Tsuchiya H. Disappearance of lung adenocarcinoma after total en bloc spondylectomy using frozen tumor-bearing vertebra for reconstruction. Eur Spine J 2016; 25: 53-7.

15. Kimura H, Fujibayashi S, Shimizu T, et al. Successful total en bloc spondylectomy of $\mathrm{T} 7$ vertebra for hepatocellular carcinoma metastasis after living donor liver transplantation. Spine. 2015; 40: E944-7.

16. Choi D, Fox Z, Albert T, et al. Rapid improvements in pain and quality of life are sustained after surgery for spinal metastases in a large prospective cohort. Br J Neurosurg 2016; 30: 337-44.

Spine Surgery and Related Research is an Open Access article distributed under the Creative Commons Attribution - NonCommercial - NoDerivatives 4.0 International License. To view the details of this license, please visit (https://creativecommons.org/licenses/by - nc - nd/4.0/). 